\title{
Free fatty acid receptor 2 and nutrient sensing: a proposed role for fibre, fermentable carbohydrates and short-chain fatty acids in appetite regulation
}

\author{
Michelle L. Sleeth, Emily L. Thompson, Heather E. Ford, Sagen E. K. Zac-Varghese and Gary Frost* \\ Department of Investigative Medicine, Imperial College London, London, UK
}

\begin{abstract}
The way in which the composition of the diet may affect appetite, food intake and body weight is now receiving considerable attention in a bid to halt the global year-on-year rise in obesity prevalence. Epidemiological evidence suggests that populations who follow a fibre-rich, traditional diet are likely to have a lower body weight and improved metabolic parameters than their Western-diet counterparts. The colonic effects of fibre, and more specifically the SCFA that the fermentation process produces, may play a role in maintaining energy homeostasis via their action on the G-coupled protein receptor free fatty acid receptor 2 (FFA2; formerly GPR43). In the present review, we summarise the evidence for and against the role of FFA2 in energy homeostasis circuits and the possible ways that these could be exploited therapeutically. We also propose that the decline in fibre content of the diet since the Industrial Revolution, particularly fermentable fractions, may have resulted in the FFA2-mediated circuits being under-utilised and hence play a role in the current obesity epidemic.
\end{abstract}

Obesity: Fibre: SCFA: Free fatty acid receptors

\section{Introduction}

The WHO declared that global childhood and adult obesity levels have reached epidemic proportions ${ }^{(1)}$ with the incidence in both developed and developing countries increasing at an alarming rate. The 2006 Health Survey for England reported obesity levels of $24 \%$ in both men and women $^{(2)}$ and current projections suggest that these figures are only set to escalate ${ }^{(3)}$. Obesity increases the risk of developing many chronic diseases including some cancers, CVD, type 2 diabetes and hypertension ${ }^{(4)}$. The cost of obesity and its associated co-morbidities is difficult to quantify, but estimates suggest that treating obesity and its consequences cost the National Health Service over $£ 991$ million annually and the UK economy $£ 7$ billion when subsequent factors such as loss of work productivity are considered $^{(5)}$. It is therefore easy to see why preventative and curative treatments for obesity are eagerly sought.

Lifestyle modification advice to reduce energy intake and increase physical activity remains the first-line treatment strategy for overweight and obesity. Although successful in the short term, proven efficacy in long-term weight maintenance is poor ${ }^{(6)}$. Weight loss through lifestyle modification is only maintained in approximately $20 \%$ of individuals at 1 -year follow-up ${ }^{(7)}$ and by 5 years, maintenance of weight loss is rarely seen ${ }^{(8-11)}$. Adjunct anti-obesity medications such as orlistat modestly aid weight loss ${ }^{(12)}$, but, to date, bariatric surgery remains the most successful long-term treatment option ${ }^{(13)}$.

Treating obesity remains difficult when the exact aetiology of the condition has yet to be elucidated. Appetite regulation has been highlighted as one of the four key determinants of obesity alongside dietary habits, physical activity and psychological ambivalence ${ }^{(5)}$. Whilst research into central nervous system (CNS) and peripheral appetiteregulatory circuits has advanced at an astonishing pace over the last two decades, it is still not clear how the innate mechanisms that served our ancestors so well can now be adapted to suit our current environment.

\section{Discussion \\ Fibre and body weight}

One food macro-component that differentiates current Westernised diets from those of the hunter-gatherer is the quantity and quality of dietary fibre. It has been estimated

\footnotetext{
Abbreviations: CNS, central nervous system; FC, fermentable carbohydrates; FFA2, free fatty acid receptor 2; FFA3, free fatty acid receptor 3; GLP, glucagon-like-peptide; 5-HT, 5-hydroxytryptamine; IR, immunoreactive; OXM, oxyntomodulin; POMC, proopiomelanocortin; PYY, peptide YY.

* Corresponding author: Professor G. Frost, fax +44 208383 8320, email g.frost@imperial.ac.uk
} 
that the hunter-gatherer Palaeolithic diet delivered more than $100 \mathrm{~g}$ fibre per $\mathrm{d}^{(14)}$. Yet, the current average American diet contains only $15 \mathrm{~g}$ fibre per $\mathrm{d}$, just half of what current US recommendations deem adequate ${ }^{(15)}$. Moreover, the type of fibres forming the larger proportion of current dietary intake is likely to be different too. The diet of the hunter-gatherer contained a greater proportion of fibre from fruits and vegetables which ferments to a greater extent than the cereal grain fibres which prevail in current Western diets ${ }^{(16)}$. Agricultural, animal husbandry and industrial reforms have all contributed towards this dietary shift ${ }^{(17)}$.

There is evidence to suggest that dietary manipulation to increase dietary fibre intake may be protective against obesity $^{(18)}$. Epidemiological studies have highlighted that diets rich in fibre are inversely correlated with body weight, $\mathrm{BMI}^{(19-21)}$ and adiposity ${ }^{(22,23)}$. Results from weightmanagement intervention studies using high-fibre foods and supplements are also encouraging ${ }^{(24-26)}$. It appears that fibre acts via numerous mechanisms to increase levels of both satiation (the satisfaction of appetite that develops during the course of eating which leads to meal termination) and satiety (the state in which further eating is inhibited and occurs as a consequence of having eaten). A classic human study showed that different apple preparations had different effects on appetite despite a constant rate of ingestion and isoenergetic portions. Subjects reported that a whole apple made them feel significantly fuller and suppressed future hunger more than apple purée, which in turn was more satiating than apple juice ${ }^{(27)}$. The increased physical disruption and removal of fibre from whole fruit to juice may be linked to a reduced satiating action. Reduced mastication, reduced gastric distension and a more rapid glycaemic response may also be contributing factors. Processes such as grain milling and carbohydrate refinement have become an intrinsic part of food manufacturing since the Industrial Revolution. This perhaps explains the positive correlation between intake of refined products and weight gain in observational studies ${ }^{(28)}$.

Not all fibre intervention studies have shown a positive correlation with weight loss or perceived satiety ${ }^{(29)}$. However, as study protocols vary considerably and rely heavily on accurate food intake reporting, this is perhaps not surprising. Howarth summarised in 2001 that the majority of fibre-supplementation studies in energy-restricted subjects showed beneficial outcomes on satiety, reduced energy intake and body weight ${ }^{(30)}$. Furthermore, these effects seem to be preserved with ad libitum energy intake. Howarth calculated from ad libitum studies available that an additional fibre intake of $14 \mathrm{~g} / \mathrm{d}$ (dietary fibre or fibre supplements) was associated with a $10 \%$ reduction in energy intake and a mean body-weight loss of $1.9 \mathrm{~kg}$ over 3.8 months, with the greatest weight loss seen in obese individuals ${ }^{(30)}$. Most studies also investigated weight change as a primary outcome.

Fibre has been proposed to inhibit excess dietary energy intake by a number of mechanisms ${ }^{(31)}$ including: (1) displacement of energy-dense foods from the diet; (2) inhibition of absorption of macronutrients at the intestinal surface; (3) an altered luminal environment; (4) an increased gastric distension. Further purported physical and hormonal effects of fibre have been reviewed in detail elsewhere ${ }^{(30,32)}$ and are summarised in Fig. 1. However, it is perhaps worth remembering that the term 'fibre' covers a vast array of substances and their differing chemical properties dictate their physiological effects. Non-fermentable fibres such us cellulose are believed to play a limited role in inhibiting excess energy intake. Whilst their non-nutritive nature allows them to cause distension and dilute the energy

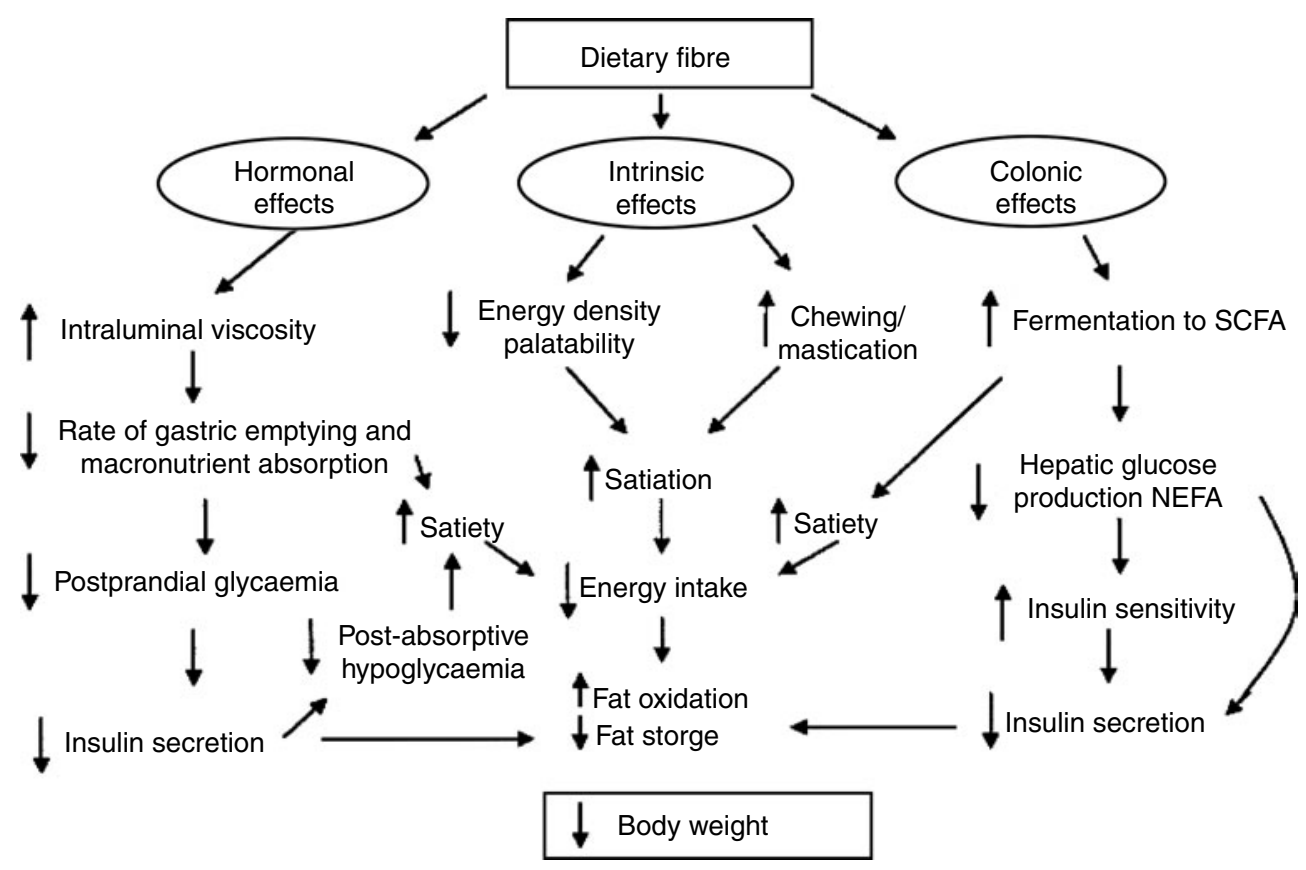

Fig. 1. Schematical summary of the hormonal, intrinsic and colonic properties of dietary fibre and how they may reduce body weight by modulation of appetite ${ }^{(32)}$. (Reproduced by permission.) 
density of foods, in rodent studies at least, it is apparent that following a period of adaptation, rodents simply consume an increased food volume to match their previous energy intake $^{(33)}$. Fermentable carbohydrates (FC) appear to also have a role in reducing food intake and therefore aiding the control of body weight and body fat as shown in multiple animal FC-supplementation studies ${ }^{(34-36)}$. Whilst the evidence in human subjects is more controversial ${ }^{(29)}, \mathrm{FC}$ or perhaps more specifically the products of colonic fermentation process do appear to play some part in the control of food intake and body weight.

\section{$S C F A$}

Recently, the colonic effects of fibre have come under fresh scrutiny. Accumulating evidence has suggested that the satiating effects of fibre may be due to SCFA, the major fermentation product of fibre ${ }^{(37)}$. By definition, all dietary fibre passes through the small intestine unaffected by human digestive processes. However, upon reaching the colon, anaerobic bacteria are able to degrade some dietary fibres via a fermentation process to yield SCFA. In general, the fermentability of soluble fibres by the colonic microbiota is much greater than that of insoluble fibres. Pectin, resistant starches, gums and polyfructans (for example, inulin) are the most highly fermented substrates, and for the purpose of the present review shall be collectively known as FC. FC yield metabolisable energy (about $2 \mathrm{kcal} / \mathrm{g} ; 8 \mathrm{~kJ} / \mathrm{g}$ ), gases $\left(\mathrm{CO}_{2}, \mathrm{H}_{2}\right.$ and $\left.\mathrm{CH}_{4}\right)$ and SCFA from fermentation reactions. However, the production of SCFA is subject to vast interindividual variation, largely dependent upon the type of FC, the host's microbiota and gut transit time (for a review of factors regulating SCFA production, see Macfarlane \& Macfarlane ${ }^{(38)}$ ).

SCFA consist of carbon chain length between C2 and C6. With insignificant quantities of SCFA coming directly from the diet, bacterial fermentation and endogenous synthesis are considered the major sources of SCFA in non-ruminant animals $^{(39,40)}$. Over $80 \%$ of SCFA present in the human colonic lumen are in the form of acetate $(\mathrm{C} 2)$, propionate (C3) and butyrate (C4) in the approximate molar concentrations of $57: 22: 21^{(41)}$. About $90 \%$ of SCFA are rapidly absorbed in the colon; butyrate is almost entirely utilised by colonocytes as their preferred energy substrate ${ }^{(42)}$. Propionate is primarily removed by the liver ${ }^{(41)}$. Peripheral blood levels are therefore low under normal physiological

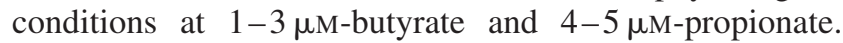
Acetate, however, passes more freely into the peripheral circulation and therefore higher plasma levels of up to $100-150 \mu \mathrm{M}$ are seen ${ }^{(43)}$. This figure can be increased up to $250 \%$ following the hepatic breakdown of ingested ethanol $^{(44)}$.

It is well documented that butyrate plays a critical role in regulating colonocyte cell proliferation, differentiation ${ }^{(42,45)}$ and inflammatory response ${ }^{(45)}$. Acetate and propionate, however, are less desirable colonic substrates ${ }^{(46)}$, so their physiological roles are proposed to be more linked to carbohydrate and lipid metabolism ${ }^{(47)}$. Their complex relationship with hepatic lipid processing has been outlined elsewhere ${ }^{(48,49)}$. SCFA have been shown in animal models to be important mediators of colonic blood flow ${ }^{(50)}$, fluid and electrolyte balance ${ }^{(51)}$ and gastrointestinal motility ${ }^{(52)}$. More recently, however, they have also been proposed as key energy homeostasis signalling molecules, feeding back important information on the nutrient milieu of the colon.

\section{SCFA receptors}

Until 2003, the G-protein-coupled receptors GPR41 and GPR43 were considered orphaned. During routine screening with bioactive compounds or 'ligand fishing' it emerged that free fatty acid receptor 3 (FFA3; formerly GPR41) and FFA2 (formerly GPR43) were activated by acetate using $\mathrm{Ca}^{2+}$ mobilisation assays in transfected human embryonic kidney (HEK293T) and CHO-K1 cells $^{(53-55)}$. In vitro activation also occurred at physiological doses with other SCFA including propionate and butyrate. FFA2 was found to have similar micromolar activation potencies for acetate, propionate and butyrate whilst FFA3 had activation in the following potency order: propionate $>$ butyrate $\gg$ acetate $^{(53,54)}$. The 100 -fold lower activation potency of FFA3 to acetate can be used diagnostically to distinguish FFA3 from FFA2 ${ }^{(53)}$. Whilst the receptors share endogenous ligands, it is apparent that their G-protein signalling mechanism differs. FFA2 and FFA3 can both signal using the pertussis toxin-sensitive $G_{i / o}$ pathway, whilst data suggest that FFA2 also possesses the ability to signal using the $\mathrm{G}_{\mathrm{q} / 11}$ pathway ${ }^{(54)}$. The physiological significance of this dual-coupled signalling mechanism present in FFA2 but not in FFA3 is not yet understood.

\section{Free fatty acid receptor 2 and appetite regulation}

The first suggestion that FFA2 may be implicated in appetite-regulatory processes was the identification of FFA2 mRNA expression in both rat whole-wall and separated mucosa samples from the distal ileum and colon ${ }^{(56)}$. These findings have since been confirmed ${ }^{(57)}$ and also reported in whole-wall samples of the human colon ${ }^{(58)}$. Recent quantitative real-time PCR anatomical profiling in mouse tissue by Regard et al. provides further comparative expression data highlighting the greatest expression levels of FFA 2 in the bone marrow and islet cells of the pancreas. Considerable quantities were also found in the white and brown adipose tissue, spleen and the large intestine ${ }^{(59)}$.

\section{Peptide $Y Y$}

In rats, FFA2 immunoreactive (IR) cells are completely co-localised with peptide YY (PYY) IR enteroendocrine L-cells of the gastrointestinal tract, with all IR FFA2-expressing cells also expressing PYY ${ }^{(56)}$. Although both neural and hormonal factors stimulate the release of PYY it is also likely that nutrients in the luminal environment induce L-cell peptide secretion of the peptide and others encoded by the proglucagon gene: glucagon-like-peptides (GLP) 1 and 2 (GLP-1, GLP-2) and oxyntomodulin (OXM) ${ }^{(60,61)}$. This co-localisation discovery in both the rat ileum and human colon may suggest that activation of FFA2 by SCFA ligands facilitates or modifies PYY secretion ${ }^{(56)}$. 
PYY release is directly proportional to the energy content of an ingested meal ${ }^{(61,62)}$ and plasma levels are reduced by fasting. The full length $\left(\mathrm{PYY}_{1-36}\right)$ and truncated $\left(\mathrm{PYY}_{3-36}\right)$ peptide forms are synthesised and secreted from L-cells throughout the entire length of the gastrointestinal tract with the highest concentrations found in the colon and rectum ${ }^{(61)}$. Lower concentrations are also seen in the $\mathrm{CNS}^{(63)}$. $\mathrm{PYY}_{3-36}$ preferentially binds to the $\mathrm{Y} 2$ receptor which has the highest levels of tissue expression in the arcuate nucleus of the hypothalamus, an important neuronal site in the central integration of appetite control ${ }^{(64)}$. Significant reductions in food intake have been demonstrated following peripheral administration of physiological levels of $\mathrm{PYY}_{3-36}$ in rodents ${ }^{(65,66)}$ and in both normal-weight and obese human subjects $^{(65)}$. Rodent data have suggested that PYY is likely to exert its hypophagic effect by increasing the expression of the anorexigenic pro-opiomelanocortin (POMC) neuropeptide populations and reducing the expression of neuropeptide $\mathrm{Y}$ within the arcuate nucleus ${ }^{(65)}$. Rodent vagotomy experiments have also highlighted the importance of the brain stem and the vagus nerve in the appetitereducing effects of $\mathrm{PYY} \mathrm{Y}^{(67)}$.

Increased plasma PYY levels have been consistently seen in $\operatorname{rats}^{(34,68,69)}$ and human subjects ${ }^{(70)}$ following FC supplementation. Moreover, direct infusion of SCFA into rabbit and rat colons has been shown to increase PYY secretion $^{(71,72)}$, suggesting that SCFA derived from the fermentation process may be responsible. Whilst therapeutically encouraging, perhaps the more clinically relevant question is: are elevated plasma PYY levels resulting from FC supplementation sufficient in magnitude to bring about a change in appetite or body-weight regulation? Ingestion of lactitol (a fermentable sugar alcohol) significantly increased postprandial PYY plasma level response in rats, and chronic consumption decreased weight gain compared with normal chow controls. Acute supplementation of lactitol in human subjects was associated with a significant attenuation of postprandial PYY decline at $5 \mathrm{~h}$ and a trend towards reduced appetite $^{(73)}$, suggesting that a physiological effect may be present after acute supplementation of relatively small doses $(15 \mathrm{~g})$ of FC.

\section{Pre-proglucagon gene products}

Enteroendocrine L-cells are also one of the major sites for expression of the proglucagon gene which encodes for GLP-1, GLP-2 and OXM. These are co-stored and co-secreted with PYY from enteroendocrine L-cells ${ }^{(74)}$. Therefore, it is possible that luminal SCFA also stimulate L-cell secretion of GLP-1 and other products of the preproglucagon gene via FFA2. GLP-1 is a potent anorexigenic hormone and incretin. It is released following nutrient ingestion in proportion to the energetic content of the meal ${ }^{(75)}$. Acute intracerebroventricular administration (icv) of GLP-1 to rodents is associated with a decline in shortterm energy intake ${ }^{(76)}$ and a reduced body weight following repeated administration ${ }^{(77)}$. Intravenous injection of GLP-1 in both lean and obese human subjects produces a dosedependent hypophagic effect ${ }^{(78)}$. The GLP-1 receptor is expressed in the pancreatic islets ${ }^{(59,79)}$, reflecting its importance as an incretin. Appreciable quantities are also seen in the hypothalamus and brainstem ${ }^{(80,81)}$. The anorectic effects of GLP-1 are abolished following vagotomy in rodents, suggesting that the interplay between the vagus and hypothalamus may be mediating the peptide's anorexigenic effect $^{(82)}$.

OXM is co-secreted with PYY and GLP-1 from the entoendocrine L-cells following nutrient ingestion. Like GLP-1, peripheral and icv administration of OXM has also been shown to reduce food intake in both human subjects and rodents ${ }^{(83-85)}$ and act as an incretin ${ }^{(86)}$. OXM is thought to signal via the GLP-1 receptor ${ }^{(85)}$, but the anorexigenic mechanism of OXM has yet to be fully characterised. Increased expression of the anorexigenic hypothalamic peptide $\alpha$-melanocyte-stimulating hormone ${ }^{(84)}$ and suppression of the orexigenic hormone ghrelin ${ }^{(83)}$ have been shown to result from peripheral OXM administration.

FC-supplementation studies have consistently been associated with increased colonic proglucagon mRNA expression $^{(34,68,69,87-90)}$. However, only some studies were able to corroborate these findings with increased circulating plasma GLP-1 levels ${ }^{(34,68-70,88,91)}$. Others have shown no effect $^{(73,92,93)}$. Nevertheless, the duration of supplementation is important to consider in the interpretation of results. Sufficient time must be given to allow for the adaptation of the gut microbiota to the additional FC within the diet for maximal fermentation ${ }^{(94)}$. Few studies have investigated the effect of SCFA on plasma OXM levels. As suggested for PYY, if GLP-1 and OXM secretion could be enhanced via FFA2 activation, the potential for dietary or pharmacological manipulation to increase satiety could be used in the treatment of obesity. Equally, with specific relevance to GLP-1 and OXM, it may be useful in potentiating insulin secretion in patients with type 2 diabetes via their incretin action.

\section{Fermentable carbohydrates and central appetite regulation}

More recently it has been suggested that FC may not only affect acute satiety signals such as PYY and GLP-1, but may also exert a more chronic action on body-weight control by indirectly altering expression of hypothalamic neuropeptides. The arcuate nucleus contains two neuronal populations, which as components of the gut-brain axis act to regulate energy balance: the anorexigenic POMC and cocaine- and amphetamine-regulated transcript (CART) neurones and the orexigenic neuropeptide $\mathrm{Y}$ and agoutirelated peptide neurones. In a recent study, Shen et al. fed one group of rats with a high-resistant starch diet $(30 \%$, $\mathrm{w} / \mathrm{w})$ and another group was fed standard chow for $65 \mathrm{~d}$. It was found that POMC mRNA expression was significantly increased in the resistant starch group compared with controls ${ }^{(95)}$. This effect was preserved in capsaicin-treated rats, suggesting that this effect was not vagally mediated. Although it is likely that SCFA pass across the bloodbrain barrier via a carrier-mediated mechanism ${ }^{(96)}$, there is little or no apparent expression of FFA2 in the hypothalamus ${ }^{(59)}$. Therefore, it may perhaps be concluded that any effects seen on hypothalamic neuropeptide expression are occurring as a consequence of increased levels of plasma PYY and GLP-1. 


\section{Free fatty acid receptor 2 activation as an energy} homeostasis mechanism

Before the displacement of fibre-rich foods during the Industrial Revolution ${ }^{(97)}$, excess food intake, i.e. a positive energy balance, would have been predictably associated with a proportional rise in fibre intake. Should our hypothesis regarding the functional role of FFA2 be correct, this resultant increase in SCFA produced in the colon leads to amplified FFA2 signalling. Up-regulation of PYY and GLP-1 expression and secretion and possibly other products of the proglucagon gene, for example OXM, would ensue. Fig. 2 illustrates that anorexigenic neural circuits are subsequently activated to reduce food intake and increase energy expenditure to restore the body back to neutral energy balance. Projection of this schematic to the current mode of Westernised, energy-dense diets disrupts this homeostatic cycle, as the inevitable parallel between energy and fibre density no longer exists. Although an increase in PYY and GLP-1 levels follows an increased energy intake, an enhanced secretion profile associated with the SCFA activation of FFA2 may be absent.

\section{SCFA and gastrointestinal motility}

A negative-feedback mechanism known as the 'ileal brake' can occur following nutrient digestion ${ }^{(98)}$; this is particularly true of fats. Various neural and hormonal signals act to slow gastrointestinal motility to enhance digestion and nutrient absorption whilst eliciting an anorexigenic effect. Yet it is apparent that SCFA may have a role in gastrointestinal motility beyond that of other fats as part of the ileal brake. The majority of work linking gastrointestinal motility and SCFA stems from ruminant animal studies ${ }^{(99)}$ where, due to differences in gut physiology, SCFA production is much greater $^{(100)}$. However, there is some evidence in non-ruminants that SCFA may regulate overall transit time of digesta through the large intestine ${ }^{(57,101)}$ and potentially contribute to

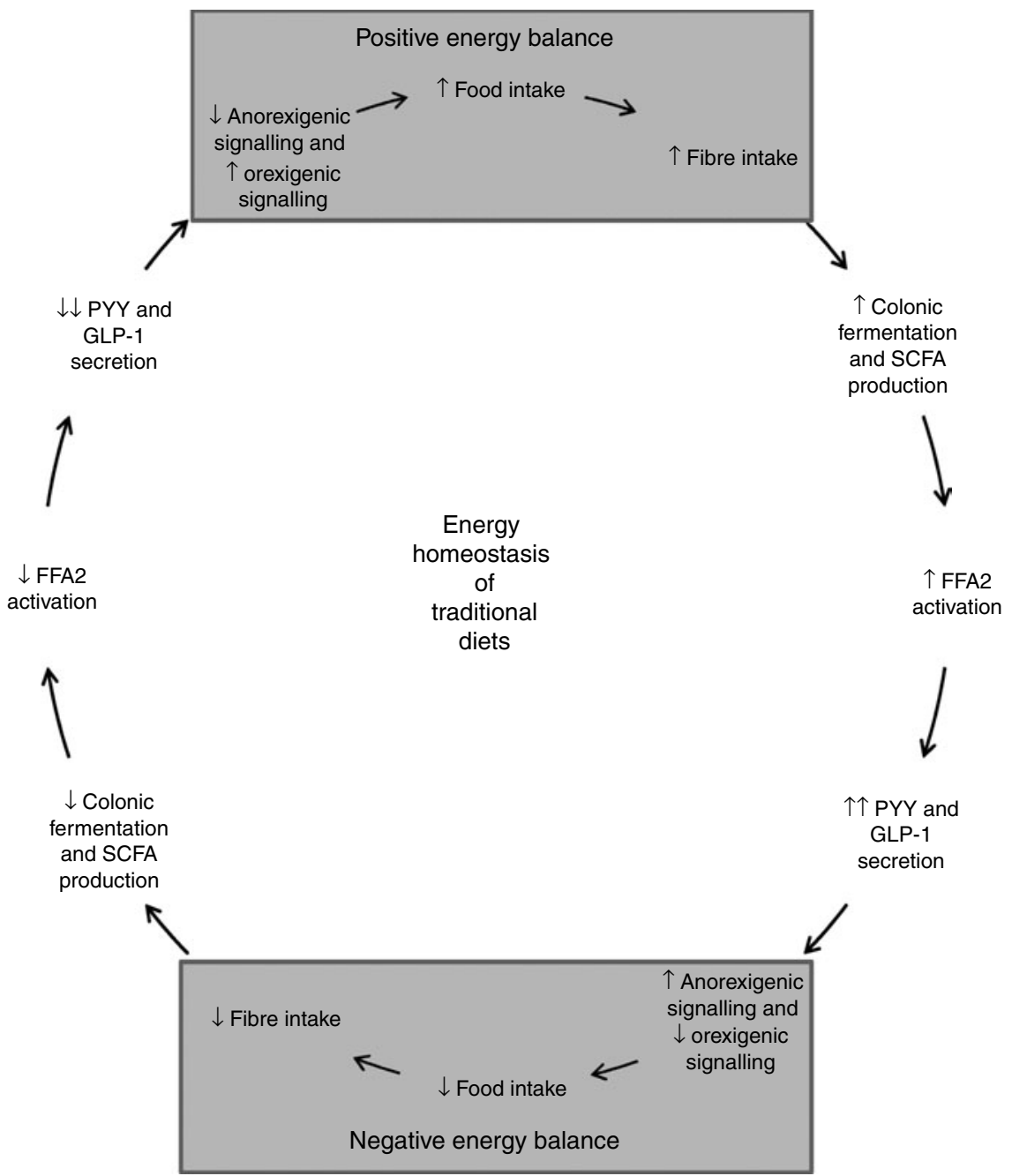

Fig. 2. A proposed role of fibre and free fatty acid receptor 2 (FFA2) activation in maintaining energy homeostasis. This projected negativefeedback-type mechanism assumes that an increase in food and energy intake within a traditional (fibre-rich) diet is associated with increased SCFA production. Thus, FFA2 is activated to increase anorexigenic signalling, increasing the secretion of peptide YY (PYY) and glucagon-like-peptide-1 (GLP-1). When a reduction in food is brought about, fibre intake consequently falls, and FFA2 activation is reduced. 
appetite regulation. Cherbut hypothesises that there are three possible mechanisms eliciting this response: (1) SCFA stimulation of vagal nerves in the gut; (2) a direct effect of SCFA on intestinal smooth muscle tone; or (3) as a consequence of the indirect changes in secretion of PYY and other regulatory peptides ${ }^{(102)}$

Perhaps given less consideration is that FFA2 may be partly controlling this effect on gastrointestinal motility. Recent findings have indicated aside from co-localisation with PYY, SCFA stimulation of FFA2 may also affect gastrointestinal 5-hydroxytryptamine (5-HT) release. 5-HT, or serotonin, is a neurotransmitter in the CNS known to modulate mood, behaviour and appetite ${ }^{(103)}$. Whilst the CNS actions of 5-HT are the most documented, $95 \%$ of endogenous 5-HT is found peripherally in the gastrointestinal tract, primarily in enterochromaffin cells but also in 5-HT-containing mucosal mast cells ${ }^{(104)}$. Mechanical and chemical stimuli during nutrient ingestion (including by SCFA) in the gut cause 5-HT to be dose-dependently released $^{(105-107)}$. Activation of the various 5-HT receptor sub-types has opposing effects on gastrointestinal motility and gastric distension. Karaki et al. have suggested that FFA2-IR cells share immunoreactivity with 5-HT-containing mucosal mast cells of the rat distal ileum and colon ${ }^{(56)}$. Therefore, SCFA activation of FFA2 may mediate the release of gut 5-HT and herald a role for FFA2 in gastric motility-mediated appetite regulation, independent of that of PYY and products of the proglucagon gene. The colocalisation of FFA2-IR cells with 5-HT-releasing cells in the human colon has yet to be confirmed ${ }^{(58)}$.

\section{Free fatty acid receptor 2 actions and the metabolic syndrome}

Independent of the effect on appetite-regulatory pathways, FFA2 may also improve certain metabolic derangements seen as part of the metabolic syndrome. The metabolic syndrome is used to describe a cluster of cardiovascular risk factors including central obesity, impaired glucose tolerance, dyslipidaemia and hypertension $^{(108)}$. Excess fat mass, characterised by both adipocyte hyperplasia and hypertrophy, is thought to partly explain why obese individuals have a greater disposition to exhibit the various components of the metabolic syndrome.

Adipose tissue is not just an energy reservoir for TAG; instead, it is now considered a complex endocrine organ. It is the site of secretion for a host of hormones, inflammatory markers and cytokines, some of which act as peripheral indicators of long-term energy balance, for example leptin ${ }^{(109)}$. Moreover, the morphology of adipocytes seems to be key factor in physiological adaption to positive energy balance. The lipotoxicity theory suggests that obesity is a state whereby adipocytes become engorged with TAG, thereby reducing the buffering capacity of adipocytes to uptake TAG in the postprandial state ${ }^{(110)}$. Consequently, TAG remain elevated and TAG deposition begins to occur in ectopic functional tissue, for example, the liver, pancreas or skeletal muscle. This is detrimental to functionality, glucose handling and insulin sensitivity of the cells.

Following the discovery of FFA2 expression in adipocytes, Hong et al. conducted a series of studies to try and elucidate a possible role of FFA2 in adipocyte functioning ${ }^{(43)}$. It was first shown that adipocyte expression of FFA2 in mice fed high-fat diets was significantly greater than that of their standard chow-fed counterparts. In 3T3-L1 cells it was found that FFA2 mRNA and PPAR $\gamma 2$ (a marker of preadipocyte differentiation) were increased following treatment with the SCFA acetate and propionate. Increased oil red $\mathrm{O}$ staining demonstrated increased fat accumulation in the cells, which was abolished with the down-regulation of FFA2 with antisense small interfering RNA. Taken together, this suggests that FFA2 and activation by SCFA may be critical in the differentiation of adipocytes, their capacity to store TAG and perhaps prevent the deposition of ectopic fat ${ }^{(111)}$

In normal health, postprandial insulin release should herald a shift in substrate utilisation from NEFA to glucose and therefore inhibit lipolysis and NEFA release ${ }^{(112)}$. However, cells that have become insulin resistant (possibly due to ectopic fat deposition) do not respond to this cue appropriately and continue to preferentially use NEFA as their energy source, causing a cluster of metabolic disturbances. FFA2 may be implicated in improving this metabolic disruption by reducing the flux of NEFA from adipocytes. In vitro, acetate and propionate were able to suppress isoproterenol-induced lipolysis in a dosedependent manner ${ }^{(43)}$. In agreement, arterio-venous sampling by Robertson et al. demonstrated in human subjects that acetate and propionate act directly on subcutaneous abdominal adipocytes to reduce NEFA flux from adipocytes ${ }^{(92)}$. More recently it has been suggested that FFA2 mediates this effect. Acetate dose-dependently reduced the release of NEFA from wild-type mouse adipocytes in vitro whilst, in vivo, intra-peritoneal (IP) injection of sodium acetate at $500 \mathrm{mg} / \mathrm{kg}$ to wild-type mice elicited a simultaneous peak of plasma acetate concentration and reduced plasma NEFA at 15 min post-injection ${ }^{(113)}$. This effect was abolished in FFA2 knockout mice, suggesting that the effects seen are occurring as a result of the direct activation of FFA2 by acetate.

The potential ability of FFA2 activation to stimulate adipogenesis and reduce lipolysis heralds a wider role for SCFA and FC in the control of the metabolic syndrome. It is intriguing that the beneficial effects of fibre supplementation on glucose control and dyslipidaemia observed in some studies ${ }^{(114)}$ may be partly attributable to the previously unconsidered effect of SCFA on adipocyte FFA2. Demonstration of relatively high tissue expression levels of FFA2 on pancreatic islet cells ${ }^{(59,115)}$ and the effect their activation has also warrants further investigation.

It is beyond the scope of the present paper to cover in detail the purported actions of the other SCFA-activated receptor FFA3. Readers are directed towards Stoddart's excellent review ${ }^{(116)}$. Whilst FFA2 and FFA3 may share endogenous ligands, there is currently insufficient data to suggest if there is an overlap in the function of the receptors. FFA3 has also been found to be expressed in the human colon $^{(117)}$. Although few data are currently available on its functionality, knockout models have suggested that it may be important in mediating the secretion of PYY(118). Another significant finding worth mentioning in brief is that of Xiong et al. ${ }^{(119)}$. They have shown that adipocyte FFA3 
activation causes an increase in leptin secretion from mouse adipocytes in vitro and in vivo following SCFA (and most potently propionate) oral administration ${ }^{(119)}$. Leptin, principally secreted from white adipose tissue, is a potent anorexigenic hormone and is a long-term and dynamic marker of body adiposity ${ }^{(120)}$. This suggests that SCFA supplementation may also act on appetite via an FFA3mediated response.

\section{Future perspectives for free fatty acid receptor 2}

Activation of colonic FFA2 by FC, SCFA, or pharmacological mimetics is a promising candidate in the fight against the current obesity onslaught. The novel synthetic allosteric agonists for FFA2 (phenylacetamides 1 and 2) have provided agents of possible pharmaceutical promise. Lee et al. demonstrated a greater activation potency of phenylacetamides 1 and 2 compared with endogenous SCFA and the ability of these compounds to activate both the $\mathrm{G}_{\mathrm{q}}$-coupled aequorin and $\mathrm{G}_{\mathrm{i}}$-coupled cyclic AMP inhibition pathways ${ }^{(121)}$. In vivo studies utilising these compounds are now eagerly awaited.

The co-localisation of FFA2 with PYY-releasing L-cells offers a further potential mechanism to link epidemiological observations of high-fibre diets and lower body weight. Diets high in FC are associated with increased PYY mRNA expression, PYY secretion and increased satiety. Whether PYY or GLP-1 could reach sufficient therapeutic levels through dietary supplementation alone, and if these physiological effects can be extrapolated directly to a reduction in food intake and body weight in humans require further exploration.

It remains a scientific challenge to study the effects of SCFA on FFA2 in isolation from the other physiological effects of FC and dietary fibre supplementation. Individual variation in host bacterial colonisation and transit time can lead to an unpredictable conversion of FC to $\mathrm{SCFA}^{(38)}$, so standardised FC doses may not necessarily produce equivalent levels of FFA2 activation. A chronic resistant starch-supplementation study in rats demonstrated increasing caecal concentrations of butyrate and dynamic shifts in the molar concentrations between the different SCFA even after 6 months of supplementation ${ }^{(122)}$. Measurement of SCFA in vivo is also complex, low concentrations are found in peripheral blood ${ }^{(123)}$ and appear to have diurnal variation related to meal pattern ${ }^{(124)}$. Whilst direct supplementation with SCFA may appear to ease these methodological troubles, oral SCFA supplements are absorbed in the small intestine and therefore will not reach the colon, the site of greatest L-cell abundance.

The quantity and molar ratio of the SCFA produced from bacterial fermentation, as mentioned previously, is dependent on many factors including the host's microbiota. Interestingly, the relative contribution of different bacterial strains to the host's overall microflora has also been independently associated with obesity. Controversial studies utilising the leptin-deficient $o b / o b$ mouse have found that the abundance of the Bacteroidetes and the Firmicutes strains of an obese mouse differs to that of lean, wild-type littermates $^{(125)}$. Furthermore, the inoculation of a germ-free mouse with ob/ob microflora induces fat gain and obesity $^{(125)}$. This is perhaps occurring as a result of increased energy yield from the digestive processes of obese mice and humans and this at least in part appears to be mediated via an increase in the production of the SCFA acetate and butyrate ${ }^{(126)}$. Obesity-associated changes in host colonic bacteria have also been demonstrated in human subjects ${ }^{(127)}$ but it is unclear whether this is a cause or effect relationship. This may be a physiological attempt to prevent future weight gain, using the possible FFA2-mediated mechanism highlighted in this paper or alternatively, a paradoxical hypothesis could be proposed whereby the obese state may be caused by a bacterial profile which has a greater efficiency to generate SCFA. Further research is still required to test both hypotheses.

The evidence in the present review outlines a case for the implication of FFA2 in the regulation of appetite and energy homeostasis through a variety of mechanisms. Whilst the purported secular trends of increasing energy intake and declining physical activity levels are the most commonly cited environmental factors in obesity development, the significance of the decline in fibre intake in the aetiology of obesity may be underestimated. The marked rise in refined product availability and subsequent fall in the consumption of fermentable fibre-rich foods since the Industrial Revolution have possibly rendered FFA2 control of appetite regulatory circuits ineffective. The prospect of using a readily accessible dietary constituent of FC to up-regulate this appetite-regulatory loop is promising of its own accord, but the possibility that there may also be adipocyte FFA2 action on improving components of the metabolic syndrome makes FFA2 targeting a high therapeutic priority.

It would be negligent not to consider the counter side to this argument that if there is a reduction in food intake brought about by FFA2 activation, this may be a host defence mechanism in response to increased colonic SCFA concentration or reduced colonic $\mathrm{pH}$ to prevent pathological changes in the gut. Common side effects experienced in human FC studies have included bloating, cramping, flatulence and soft stools ${ }^{(128)}$. It is perhaps important to remember that the colon is an important constituent of the digestive, endocrine and immunological systems and, therefore, changing the colonic environment to favour one such system may not necessarily benefit another. Chronic in vivo studies measuring histological and immunological parameters are required to investigate this further. It is also worth considering that a lack of the enzyme propionyl CoA carboxylase in the newborn allows propionic acid levels to build to fatal levels in the blood ${ }^{(129)}$. This recessive condition leads to the development of hypophagia, vomiting, dehydration, lethargy, metabolic acidosis, encephalopathy and death. Therefore the potential clinical dangers of purposefully elevating circulating SCFA should be carefully considered.

\section{Future research needs}

FFA2 research must now be aimed at proving whether the links proposed between FFA2 activation and PYY, GLP-1 and 5-HT exert appreciable effects on satiety and body weight and whether they are therapeutically exploitable. Dose-finding experiments in human subjects are essential 
for elucidating a dose which exerts physiological benefits on energy homeostasis but not at the expense of gastrointestinal discomfort or pathological changes in gut microstructure. While the current evidence base is insufficient to warrant SCFA supplementation, strategies to promote traditional diets based on whole grains, fruit, vegetables and unrefined products appear to offer some protection from the development of obesity.

\section{Acknowledgements}

The present review was funded by programme grants from the Medical Research Council (G7811974) and Wellcome Trust $(072643 / \mathrm{Z} / 03 / \mathrm{Z})$ and by a European Union FP6 Integrated Project Grant (LSHM-CT-2003-503041). We are also grateful for support from the National Institute for Health Research (NIHR) Biomedical Research Centre funding scheme. G. F. is supported by an NIHR Senior Investigator Award and S. E. K. Z.-V. is a Wellcome Trust Clinical Training Fellow.

All authors contributed to the development, writing and review of this paper. M. L. S. led and coordinated the writing of the review.

We confirm that there are no conflicts of interest with any of the contributing authors in the content of the paper.

\section{References}

1. WHO Consultation on Obesity (2000) Obesity: Preventing and Managing the Global Epidemic: Report of a WHO Consultation. World Health Organization Technical Report Series no. 894. Geneva: WHO.

2. Joint Health Surveys Unit (2008) Health Survey for England 2006. Cardiovascular Disease and Risk Factors. Leeds: The Information Centre.

3. McPherson K, Marsh T \& Brown M (2008) Foresight. Tackling Obesities: Future Choices - Modelling Future Trends in Obesity and the Impact on Health, 2nd ed. London: Government Office for Science.

4. Must A, Spadano J, Coakley EH, et al. (1999) The disease burden associated with overweight and obesity. JAMA 282, $1523-1529$.

5. Butland B, Jebb S, Kopelman P, et al. (2008) Foresight. Tackling Obesities: Future Choices - Project Report. http:// www.foresight.gov.uk/Obesity/17.pdf

6. Dansinger ML, Tatsioni A, Wong JB, et al. (2007) Metaanalysis: the effect of dietary counseling for weight loss. Ann Intern Med 147, 41-50.

7. Wing RR \& Phelan S (2005) Long-term weight loss maintenance. Am J Clin Nutr 82, 222S-225S.

8. Field AE, Wing RR, Manson JE, et al. (2001) Relationship of a large weight loss to long-term weight change among young and middle-aged US women. Int J Obes Relat Metab Disord 25, 1113-1121.

9. Sarlio-Lahteenkorva S, Rissanen A \& Kaprio J (2000) A descriptive study of weight loss maintenance: 6 and 15 year follow-up of initially overweight adults. Int $J$ Obes Relat Metab Disord 24, 116-125.

10. Stalonas PM, Perri MG \& Kerzner AB (1984) Do behavioral treatments of obesity last? A five-year follow-up investigation. Addict Behav 9, 175-183.

11. Wadden TA, Sternberg JA, Letizia KA, et al. (1989) Treatment of obesity by very low calorie diet, behavior therapy, and their combination: a five-year perspective. Int $J$ Obes 13, Suppl. 2, 39-46.

12. Rucker D, Padwal R, Li SK, et al. (2007) Long term pharmacotherapy for obesity and overweight: updated metaanalysis. BMJ 335, 1194-1199.

13. Sjostrom L, Lindroos AK, Peltonen M, et al. (2004) Lifestyle, diabetes, and cardiovascular risk factors 10 years after bariatric surgery. $N$ Engl J Med 351, 2683-2893.

14. Eaton SB (1990) Fibre intakes in prehistoric times. In Dietary Fibre Perspectives, pp. 27-40 [AR Leeds, editor]. London: John Libbey.

15. Institute of Medicine (2005) Dietary Reference Intakes for Energy, Carbohydrate, Fiber, Fat, Fatty Acids, Cholesterol, Protein, and Amino Acids (Macronutrients). Washington, DC: The National Academies Press.

16. Eaton SB (2006) The ancestral human diet: what was it and should it be a paradigm for contemporary nutrition? Proc Nutr Soc 65, 1-6.

17. Eaton SB \& Konner M (1985) Paleolithic nutrition. A consideration of its nature and current implications. $N$ Engl J Med 312, 283-289.

18. World Health Organization (2003) Diet, Nutrition and the Prevention of Chronic Diseases. Joint WHO/FAO Expert Consultation. WHO Technical Report Series no. 916. Geneva: WHO.

19. Appleby PN, Thorogood M, Mann JI, et al. (1998) Low body mass index in non-meat eaters: the possible roles of animal fat, dietary fibre and alcohol. Int $J$ Obes $\mathbf{2 2}$, 454-460.

20. Ludwig DS, Pereira MA, Kroenke CH, et al. (1999) Dietary fiber, weight gain, and cardiovascular disease risk factors in young adults. JAMA 282, 1539-1546.

21. Maskarinec G, Takata Y, Pagano I, et al. (2006) Trends and dietary determinants of overweight and obesity in a multiethnic population. Obesity (Silver Spring) 14, 717-726.

22. Nelson LH \& Tucker LA (1996) Diet composition related to body fat in a multivariate study of 203 men. J Am Diet Assoc 96, 771-777.

23. Kromhout D, Bloemberg B, Seidell JC, et al. (2001) Physical activity and dietary fiber determine population body fat levels: the Seven Countries Study. Int J Obes 25, 301-306.

24. Ryttig KR, Tellnes G, Haegh L, et al. (1989) A dietary fibre supplement and weight maintenance after weight reduction: a randomized, double-blind, placebo-controlled long-term trial. Int J Obes 13, 165-171.

25. Rigaud D, Ryttig KR, Angel LA, et al. (1990) Overweight treated with energy restriction and a dietary fibre supplement: a 6-month randomized, double-blind, placebo-controlled trial. Int J Obes 14, 763-769.

26. Tucker LA \& Thomas KS (2009) Increasing total fiber intake reduces risk of weight and fat gains in women. $J$ Nutr 139, 576-581.

27. Haber GB, Heaton KW, Murphy D, et al. (1977) Depletion and disruption of dietary fibre: effects on satiety, plasma-glucose, and serum-insulin. Lancet 310, 679-682.

28. Liu S, Willett WC, Manson JE, et al. (2003) Relation between changes in intakes of dietary fiber and grain products and changes in weight and development of obesity among middle-aged women. Am J Clin Nutr 78, 920-927.

29. Howarth NC, Saltzman E, McCrory MA, et al. (2003) Fermentable and nonfermentable fiber supplements did not alter hunger, satiety or body weight in a pilot study of men and women consuming self-selected diets. J Nutr 133, $3141-3144$. 
30. Howarth N (2001) Dietary fiber and weight regulation. Nutr Rev 59, 129-139.

31. Heaton KW (1973) Food fibre as an obstacle to energy intake. Lancet ii, 1418-1421.

32. Slavin JL (2005) Dietary fiber and body weight. Nutrition 21, 411-418.

33. Roy HJ, Keenan MJ, Zablah-Pimentel E, et al. (2003) Adult female rats defend appropriate energy intake after adaptation to dietary energy. Obes Res 11, 1214-1222.

34. Keenan MJ, Zhou J, McCutcheon KL, et al. (2006) Effects of resistant starch, a non-digestible fermentable fiber, on reducing body fat. Obesity (Silver Spring) 14, $1523-1534$.

35. Cani PD, Neyrinck AM, Maton N, et al. (2005) Oligofructose promotes satiety in rats fed a high-fat diet: involvement of glucagon-like peptide-1. Obes Res 13, 1000-1007.

36. Perrigue MM, Monsivais P \& Drewnowski A (2009) Added soluble fiber enhances the satiating power of lowenergy-density liquid yogurts. J Am Diet Assoc 109, $1862-1868$.

37. Hamer HM, Jonkers D, Venema K, et al. (2008) Review article: the role of butyrate on colonic function. Aliment Pharmacol Ther 27, 104-119.

38. Macfarlane S \& Macfarlane GT (2003) Regulation of short-chain fatty acid production. Proc Nutr Soc 62, 67-72.

39. Ballard FJ (1972) Supply and utilization of acetate in mammals. Am J Clin Nutr 25, 773-779.

40. Pouteau E, Nguyen P, Ballevre O, et al. (2003) Production rates and metabolism of short-chain fatty acids in the colon and whole body using stable isotopes. Proc Nutr Soc 62, 87-93.

41. Cummings JH, Pomare EW, Branch WJ, et al. (1987) Short chain fatty acids in human large intestine, portal, hepatic and venous blood. Gut 28, 1221-1227.

42. Roediger WE (1980) Role of anaerobic bacteria in the metabolic welfare of the colonic mucosa in man. Gut 21, $793-798$.

43. Hong YH, Nishimura Y, Hishikawa D, et al. (2005) Acetate and propionate short chain fatty acids stimulate adipogenesis via GPCR43. Endocrinology 146, 5092-5099.

44. Siler SQ, Neese RA \& Hellerstein MK (1999) De novo lipogenesis, lipid kinetics, and whole-body lipid balances in humans after acute alcohol consumption. Am J Clin Nutr 70, 928-936.

45. Topping DL \& Clifton PM (2001) Short-chain fatty acids and human colonic function: roles of resistant starch and nonstarch polysaccharides. Physiol Rev 81, 1031-1064.

46. Roediger WE (1982) Utilization of nutrients by isolated epithelial cells of the rat colon. Gastroenterology 83, 424-429.

47. Wolever TM, Spadafora P \& Eshuis H (1991) Interaction between colonic acetate and propionate in humans. Am J Clin Nutr 53, 681-687.

48. Wolever TM (1995) Short-chain fatty acids and carbohydrate metabolism. In Physiological and Clinical Aspects of Short-Chain Fatty Acids, 1st ed., pp. 483-493 [JH Cummings and JL Rombeau, editors]. Cambridge: Cambridge University Press.

49. Topping DL \& Pant I (1995) Short-chain fatty acids and hepatic lipid metabolism: experimental studies. In Physiological and Clinical Aspects of Short-Fatty Acids, 1st ed., pp. 495-507 [JH Cummings, JL Rombeau and T Sakata, editors]. Cambridge: Cambridge University Press.

50. Kvietys PR \& Granger DN (1981) Effect of volatile fatty acids on blood flow and oxygen uptake by the dog colon. Gastroenterology 80, 962-969.
51. Binder HJ \& Mehta P (1989) Short-chain fatty acids stimulate active sodium and chloride absorption in vitro in the rat distal colon. Gastroenterology 96, 989-996.

52. Yajima T (1984) Effect of sodium propionate on the contractile response of the rat ileum in situ. Jpn J Pharmacol 35, 265-271.

53. Brown AJ, Goldsworthy SM, Barnes AA, et al. (2003) The orphan G protein-coupled receptors GPR41 and GPR43 are activated by propionate and other short chain carboxylic acids. J Biol Chem 278, 11312-11319.

54. Le Poul E, Loison C, Struyf S, et al. (2003) Functional characterization of human receptors for short chain fatty acids and their role in polymorphonuclear cell activation. J Biol Chem 278, 25481-25489.

55. Nilsson NE, Kotarsky K, Owman C, et al. (2003) Identification of a free fatty acid receptor, FFA2R, expressed on leukocytes and activated by short-chain fatty acids. Biochem Biophys Res Comm 303, 1047-1052.

56. Karaki SS, Mitsui R, Hayashi H, et al. (2006) Short-chain fatty acid receptor, GPR43, is expressed by enteroendocrine cells and mucosal mast cells in rat intestine. Cell Tissue Res 324, 353-360.

57. Dass NB, John AK, Bassil AK, et al. (2007) The relationship between the effects of short-chain fatty acids on intestinal motility in vitro and GPR43 receptor activation. Neurogastroenterol Motil 19, 66-74.

58. Karaki Si, Tazoe H, Hayashi H, et al. (2008) Expression of the short-chain fatty acid receptor, GPR43, in the human colon. J Mol Histol 39, 135-142.

59. Regard JB, Sato IT \& Coughlin SR (2008) Anatomical profiling of $\mathrm{G}$ protein-coupled receptor expression. Cell 135, 561-571.

60. Greeley GH Jr, Jeng YJ, Gomez G, et al. (1989) Evidence for regulation of peptide-YY release by the proximal gut. Endocrinology 124, 1438-1443.

61. Adrian TE, Ferri GL, Bacarese-Hamilton AJ, et al. (1985) Human distribution and release of a putative new gut hormone, peptide YY. Gastroenterology 89, 1070-1077.

62. Pedersen-Bjergaard U, Host U, Kelbaek H, et al. (1996) Influence of meal composition on postprandial peripheral plasma concentrations of vasoactive peptides in man. Scand J Clin Lab Invest 56, 497-503.

63. Broome M, Hokfelt T \& Terenius L (1985) Peptide YY (PYY)-immunoreactive neurons in the lower brain stem and spinal cord of rat. Acta Physiol Scand 125, 349-352.

64. Broberger C, Landry M, Wong H, et al. (1997) Subtypes Y1 and $\mathrm{Y} 2$ of the neuropeptide $\mathrm{Y}$ receptor are respectively expressed in pro-opiomelanocortin- and neuropeptideY-containing neurons of the rat hypothalamic arcuate nucleus. Neuroendocrinology 66, 393-408.

65. Batterham RL, Cowley MA, Small CJ, et al. (2002) Gut hormone PYY(3-36) physiologically inhibits food intake. Nature 418, 650-654.

66. Chelikani PK, Haver AC \& Reidelberger RD (2005) Intravenous infusion of peptide YY(3-36) potently inhibits food intake in rats. Endocrinology 146, 879-888.

67. Koda S, Date Y, Murakami N, et al. (2005) The role of the vagal nerve in peripheral $\mathrm{PYY}_{3-36}$-induced feeding reduction in rats. Endocrinology 146, 2369-2375.

68. Delzenne NM, Cani PD, Daubioul C, et al. (2005) Impact of inulin and oligofructose on gastrointestinal peptides. $\mathrm{Br} J$ Nutr 93, Suppl. 1, S157-S161.

69. Zhou J, Martin RJ, Tulley RT, et al. (2008) Dietary resistant starch upregulates total GLP-1 and PYY in a sustained day-long manner through fermentation in rodents. Am J Physiol Endocrinol Metab 295, E1160-E1166. 
70. Greenway F, O’Neil CE, Stewart L, et al. (2007) Fourteen weeks of treatment with Viscofiber increased fasting levels of glucagon-like peptide-1 and peptide-YY. J Med Food 10, $720-724$.

71. Longo WE, Ballantyne GH, Savoca PE, et al. (1991) Short-chain fatty-acid release of peptide-YY in the isolated rabbit distal colon. Scand J Gastroenterol 26, 442-448.

72. Cherbut C, Ferrier L, Roze C, et al. (1998) Short-chain fatty acids modify colonic motility through nerves and polypeptide YY release in the rat. Am J Physiol 275, G1415-G1422.

73. Gee JM \& Johnson IT (2005) Dietary lactitol fermentation increases circulating peptide YY and glucagon-like peptide-1 in rats and humans. Nutrition 21, 1036-1043.

74. Kim BJ, Carlson OD, Jang HJ, et al. (2005) Peptide YY is secreted after oral glucose administration in a genderspecific manner. J Clin Endocrinol Metab 90, 6665-6671.

75. Elliott RM, Morgan LM, Tredger JA, et al. (1993) Glucagon-like peptide-1 (7-36) amide and glucosedependent insulinotropic polypeptide secretion in response to nutrient ingestion in man: acute post-prandial and 24-h secretion patterns. J Endocrinol 138, 159-166.

76. Turton MD, O'Shea D, Gunn I, et al. (1996) A role for glucagon-like peptide- 1 in the central regulation of feeding. Nature 379, 69-72.

77. Davis HR Jr, Mullins DE, Pines JM, et al. (1998) Effect of chronic central administration of glucagon-like peptide-1 (7-36) amide on food consumption and body weight in normal and obese rats. Obes Res 6, 147-156.

78. Verdich C, Flint A, Gutzwiller JP, et al. (2001) A metaanalysis of the effect of glucagon-like peptide-1 (7-36) amide on ad libitum energy intake in humans. $J$ Clin Endocrinol Metab 86, 4382-4389.

79. Bullock BP, Heller RS \& Habener JF (1996) Tissue distribution of messenger ribonucleic acid encoding the rat glucagon-like peptide-1 receptor. Endocrinology 137, 2968-2978.

80. Shimizu I, Hirota M, Ohboshi C, et al. (1987) Identification and localization of glucagon-like peptide- 1 and its receptor in rat brain. Endocrinology 121, 1076-1082.

81. Goke R, Larsen PJ, Mikkelsen JD, et al. (1995) Distribution of GLP-1 binding sites in the rat brain: evidence that exendin- 4 is a ligand of brain GLP-1 binding sites. Eur $J$ Neurosci 7, 2294-2300.

82. Abbott CR, Monteiro M, Small CJ, et al. (2005) The inhibitory effects of peripheral administration of peptide YY(3-36) and glucagon-like peptide-1 on food intake are attenuated by ablation of the vagal-brainstemhypothalamic pathway. Brain Res 1044, 127-131.

83. Cohen MA, Ellis SM, Le Roux CW, et al. (2003) Oxyntomodulin suppresses appetite and reduces food intake in humans. J Clin Endocrinol Metab 88, 4696-4701.

84. Dakin CL, Small CJ, Batterham RL, et al. (2004) Peripheral oxyntomodulin reduces food intake and body weight gain in rats. Endocrinology 145, 2687-2695.

85. Baggio LL, Huang Q, Brown TJ, et al. (2004) Oxyntomodulin and glucagon-like peptide-1 differentially regulate murine food intake and energy expenditure. Gastroenterology 127, $546-558$.

86. Schjoldager BT, Baldissera FG, Mortensen PE, et al. (1988) Oxyntomodulin: a potential hormone from the distal gut. Pharmacokinetics and effects on gastric acid and insulin secretion in man. Eur J Clin Invest 18, 499-503.

87. Delmee E, Cani PD, Gual G, et al. (2006) Relation between colonic proglucagon expression and metabolic response to oligofructose in high fat diet-fed mice. Life Sci 79, $1007-1013$.
88. Cani PD, Dewever C \& Delzenne NM (2004) Inulin-type fructans modulate gastrointestinal peptides involved in appetite regulation (glucagon-like peptide-1 and ghrelin) in rats. Br J Nutr 92, 521-526.

89. Massimino SP, McBurney MI, Field CJ, et al. (1998) Fermentable dietary fiber increases GLP-1 secretion and improves glucose homeostasis despite increased intestinal glucose transport capacity in healthy dogs. J Nutr 128, 1786-1793.

90. Zhou J, Hegsted M, McCutcheon KL, et al. (2006) Peptide YY and proglucagon mRNA expression patterns and regulation in the gut. Obesity (Silver Spring) 14, 683-689.

91. Piche T, des Varannes SB, Sacher-Huvelin S, et al. (2003) Colonic fermentation influences lower esophageal sphincter function in gastroesophageal reflux disease. Gastroenterology 124, 894-902.

92. Robertson MD, Bickerton AS, Dennis AL, et al. (2005) Insulin-sensitizing effects of dietary resistant starch and effects on skeletal muscle and adipose tissue metabolism. Am J Clin Nutr 82, 559-567.

93. Frost G, Brynes A \& Leeds A (1999) Effect of large bowel fermentation on insulin, glucose, free fatty acids, and glucagon-like peptide 1 (7-36) amide in patients with coronary heart disease. Nutrition 15, 183-188.

94. May T, Mackie RI, Fahey GC Jr, et al. (1994) Effect of fiber source on short-chain fatty acid production and on the growth and toxin production by Clostridium difficile. Scand J Gastroenterol 29, 916-922.

95. Shen L, Keenan MJ, Martin RJ, et al. (2009) Dietary resistant starch increases hypothalamic POMC expression in rats. Obesity (Silver Spring) 17, 40-45.

96. Oldendorf WH (1973) Carrier-mediated blood-brain barrier transport of short-chain monocarboxylic organic acids. Am J Physiol 224, 1450-1453.

97. Cordain L, Eaton SB, Sebastian A, et al. (2005) Origins and evolution of the Western diet: health implications for the 21st century. Am J Clin Nutr 81, 341-354.

98. Van Citters GW \& Lin HC (1999) The ileal brake: a fifteen-year progress report. Curr Gastroenterol Rep 1, 404-409.

99. Kendall PE \& McLeay LM (1996) Excitatory effects of volatile fatty acids on the in vitro motility of the rumen of sheep. Res Vet Sci 61, 1-6.

100. Bergman EN (1990) Energy contributions of volatile fatty acids from the gastrointestinal tract in various species. Physiol Rev 70, 567-590.

101. Tazoe H, Otomo Y, Kaji I, et al. (2008) Roles of short-chain fatty acids receptors, GPR41 and GPR43 on colonic functions. J Physiol Pharmacol 59, Suppl. 2, 251-262.

102. Cherbut C (1995) Effects of short-chain fatty acids on gastrointestinal motility. In Physiological and Clinical Aspects of Short-Chain Fatty Acids, 1st ed., pp. 191-207 [JH Cummings, JL Rombeau and T Sakata, editors]. Cambridge: Cambridge University Press.

103. Berger M, Gray JA \& Roth BL (2009) The expanded biology of serotonin. Ann Rev Med 60, 355.

104. Kim DY \& Camilleri M (2000) Serotonin: a mediator of the brain-gut connection. Am J Gastroenterol 95, 2698-2709.

105. Zhu JX, Wu XY, Owyang C, et al. (2001) Intestinal serotonin acts as a paracrine substance to mediate vagal signal transmission evoked by luminal factors in the rat. $J$ Physiol 530, 431-442.

106. Martin DC, Magnant AD \& Kellum JM Jr (1989) Luminal hypertonic solutions stimulate concentration-dependent duodenal serotonin release. Surgery 106, 325-331.

107. Fukumoto S, Tatewaki M, Yamada T, et al. (2003) Short-chain fatty acids stimulate colonic transit via 
intraluminal 5-HT release in rats. Am J Physiol Regul Integr Comp Physiol 284, R1269-R1276.

108. Grundy SM, Brewer HB Jr, Cleeman JI, et al. (2004) Definition of metabolic syndrome: Report of the National Heart, Lung, and Blood Institute/American Heart Association Conference on scientific issues related to definition. Arterioscler Thromb Vasc Biol 24, e13-e18.

109. Tilg H \& Moschen AR (2006) Adipocytokines: mediators linking adipose tissue, inflammation and immunity. Nat Rev Immunol 6, 772-783.

110. Goossens GH (2008) The role of adipose tissue dysfunction in the pathogenesis of obesity-related insulin resistance. Physiol Behav 94, 206-218.

111. Robertson M (2007) Metabolic cross talk between the colon and the periphery: implications for insulin sensitivity. Proc Nutr Soc 66, 351-361.

112. Frayn KN (2003) Integration of fat, carbohydrate and protein metabolism in the whole body. In Metabolic Regulation: a Human Perspective, pp. 151-191 [KN Frayn, editor]. Oxford: Blackwell Science.

113. Ge H, Li X, Weiszmann J, et al. (2008) Activation of GPR43 in adipocytes leads to inhibition of lipolysis and suppression of plasma free fatty acids. Endocrinology 149, 4519-4526.

114. Chandalia M, Garg A, Lutjohann D, et al. (2000) Beneficial effects of high dietary fiber intake in patients with type 2 diabetes mellitus. $N$ Engl J Med 342, 1392-1398.

115. Leonard JN \& Hakak Y (2006) (WO/2006/036688) GPR43 and modulators thereof for the treatment of metabolicrelated disorders. http://www.wipo.int/pctdb/en/wo. jsp?wo $=2006036688$

116. Stoddart LA, Smith NJ \& Milligan G (2008) International Union of Pharmacology. LXXI. Free fatty acid receptors FFA1, -2, and -3: pharmacology and pathophysiological functions. Pharmacol Rev 60, 405-417.

117. Tazoe H, Otomo Y, Karaki S, et al. (2009) Expression of short-chain fatty acid receptor GPR41 in the human colon. Biomed Res 30, 149-156.

118. Samuel BS, Shaito A, Motoike T, et al. (2008) Effects of the gut microbiota on host adiposity are modulated by the short-chain fatty-acid binding $\mathrm{G}$ protein-coupled receptor, Gpr41. Proc Natl Acad Sci U S A 105, 16767-16772.

119. Xiong Y, Miyamoto N, Shibata K, et al. (2004) Short-chain fatty acids stimulate leptin production in adipocytes through the G protein-coupled receptor GPR41. Proc Natl Acad Sci U S A 101, 1045-1050.

120. Maffei M, Halaas J, Ravussin E, et al. (1995) Leptin levels in human and rodent: measurement of plasma leptin and ob RNA in obese and weight-reduced subjects. Nat Med 1, 1155-1161.

121. Lee T, Schwandner R, Swaminath G, et al. (2008) Identification and functional characterization of allosteric agonists for the $\mathrm{G}$ protein-coupled receptor FFA2. Mol Pharmacol 74, 1599-1609.

122. Le Blay G, Michel C, Blottière HM, et al. (1999) Enhancement of butyrate production in the rat caecocolonic tract by long-term ingestion of resistant potato starch. $\mathrm{Br} \mathrm{J}$ Nutr 82, 419-426.

123. Pomare EW, Branch WJ \& Cummings JH (1985) Carbohydrate fermentation in the human colon and its relation to acetate concentrations in venous blood. $J$ Clin Invest 75, 1448-1454.

124. Wolever TMS, Josse RG, Leiter LA, et al. (1997) Time of day and glucose tolerance status affect serum short-chain fatty concentrations in humans. Metabolism 46, 805-811.

125. Turnbaugh PJ, Ley RE, Mahowald MA, et al. (2006) An obesity-associated gut microbiome with increased capacity for energy harvest. Nature 444, 1027-1031.

126. Samuel BS \& Gordon JI (2006) A humanized gnotobiotic mouse model of host-archaeal-bacterial mutualism. Proc Natl Acad Sci U S A 103, 10011-10016.

127. Turnbaugh PJ, Hamady M, Yatsunenko T, et al. (2009) A core gut microbiome in obese and lean twins. Nature 457, 480-484.

128. Davidson MH \& Maki KC (1999) Effects of dietary inulin on serum lipids. J Nutr 129, 1474.

129. Hsia YE, Scully KJ \& Rosenberg LE (1971) Inherited propionyl-CoA carboxylase deficiency in 'ketotic hyperglycinemia'. J Clin Invest 50, 127-130. 